\title{
A PERMANÊNCIA DE ESTUDANTES COTISTAS NA UFPB EM CURSOS DE ALTO E BAIXO PRESTÍGIO SOCIAL
}

\author{
The stay of quota students at UFPB in high and low social prestige courses
}

La estancia de estudiantes de cuota en UFPB en cursos de prestigio social alto y bajo

Edineide Jezine ${ }^{*}$

Sânya Teles Barbosa ${ }^{* *}$

\begin{abstract}
Resumo
O artigo objetiva discutir a permanência dos sujeitos ingressos por políticas de cotas no contexto da expansão do sistema de ensino superior, associado às políticas de democratização do acesso e inclusão social. Baseia-se na premissa de que as políticas de expansão da década de 1990 favoreceram a constituição de um sistema de ensino superior híbrido, dada a expansão do acesso, a estruturação pelos setores público e privado e as políticas de inclusão social. O lócus de análise é a Universidade Federal da Paraíba (UFPB) e os cursos de Pedagogia e Direito (Campus I), cursos considerados de baixo e alto prestígio social para o mercado de bens simbólicos, respectivamente. A pesquisa caracteriza uma abordagem qualitativa, exploratória e analítica, fundamentada no pensamento de Bourdieu a partir das categorias teóricas de capital simbólico, capital cultural e prestígio social. Para a coleta de dados foi aplicada a "Escala para Avaliação da Permanência Discente" (CASTELO BRANCO; NAKAMURA; JEZINE, 2017), na qual buscamos traçar o perfil dos entrevistados pré-concluintes e concluintes, a fim de reconhecer os fatores institucionais que contribuem para a permanência. Nesses termos, os dados indicam que o acesso ou não a bens culturais gera diferenças sociais que podem ser minimizadas a partir de políticas que consideram as distintas oportunidades.
\end{abstract}

PALAVRAS-CHAVE: Ensino Superior. Permanência e prestígio social

\begin{abstract}
The article aims to discuss the permanence of the subjects issued by quota policies in the context of the expansion of the higher education system, associated with policies of democratization of access and social inclusion. It is based on the premise that the expansion policies of the 1990s favored the constitution of a hybrid higher education system, given the expansion of access, the structuring by the public and private sectors and social inclusion policies. The locus of analysis is the Federal University of Paraíba (UFPB) and the courses of Pedagogy and Law Campus I, courses considered low and high social prestige, respectively, for the market of symbolic goods. The research is characterized under a qualitative, exploratory and analytical approach, based on Bourdieu's thinking from the theoretical categories of symbolic capital, cultural capital and social prestige. For data collection, the "Evaluation scale for the permanence of students in higher education" was applied (CASTELO BRANCO; NAKAMURA; JEZINE, 2017), in which we seek to trace the profile of the interviewees who pre-graduate and graduating, in order to recognize the institutional factors that contribute to the permanence. In these terms, the data indicate access or not to cultural goods generates social differences that can be minimized from policies that consider differences in opportunities.
\end{abstract}

KEYWORDS: Higher Education. Permanence and social prestige

\footnotetext{
*Doutora em Sociologia. Docente vinculada à Universidade Federal da Paraíba (UFPB). E-mail: edjezine@gmail.com. Orcid: https://orcid.org/0000-0002-0180-0347

** Graduada em Pedagogia. Bolsista PIBIC vinculada à Universidade Federal da Paraíba (UFPB). E-mail: sanyateles@gmail.com. Orcid: https://orcid.org/0000-0002-2998-4539
} 


\section{Resumen}

El artículo tiene como objetivo discutir la permanencia de los temas emitidos por las políticas de cuotas en el contexto de la expansión del sistema de educación superior, asociado con las políticas de democratización del acceso y la inclusión social. Se basa en la premisa de que las políticas de expansión de la década de 1990 favorecieron la constitución de un sistema híbrido de educación superior, dada la expansión del acceso, la estructuración por parte de los sectores público y privado y las políticas de inclusión social. El locus de análisis es la Universidad Federal de Paraíba (UFPB) y los cursos de Pedagogía y Derecho Campus I, cursos considerados de bajo y alto prestigio social, respectivamente, para el mercado de bienes simbólicos. La investigación se caracteriza por un enfoque cualitativo, exploratorio y analítico, basado en el pensamiento de Bourdieu a partir de las categorías teóricas de capital simbólico, capital cultural y prestigio social. Para la recopilación de datos, se aplicó la "Escala de evaluación para la permanencia de los estudiantes en la educación superior" (CASTELO BRANCO; NAKAMURA y JEZINE, 2017), en la que buscamos rastrear el perfil de los entrevistados que gradúan, con el fin de reconocer los factores institucionales que contribuyen a la permanencia. En estos términos, los datos indican que el acceso o no a bienes culturales genera diferencias sociales que pueden ser minimizadas a partir de políticas que tienen en cuenta las diferentes oportunidades.

PALABRAS CLAVE: Educación superior. Permanencia y prestigio social

\section{INTRODUÇÃO}

A temática da permanência em cursos superiores ganha relevância no contexto das políticas de expansão e democratização do acesso ao sistema de educação superior em que buscam ampliar as possibilidades do ingresso de jovens e adultos em contexto de desigualdade social.

As políticas da década de 1990 têm contribuído para a formação de um sistema de educação superior híbrido em face da expansão do acesso de diferentes públicos, estruturado por setor público e privado e políticas de inclusão social. As diretrizes para a expansão do sistema de educação superior amparam-se na aprovação da Lei de Diretrizes e Bases Nacional da Educação (LDB N 9394/96), que, ao favorecer a oferta de vagas em cursos superiores acaba por contribuir para a dualidade do sistema e expansão do setor privado de ensino. O Censo da Educação Superior 2018 (BRASIL, 2019) aponta para o total de 2.537 Instituições de Educação Superior (IES), sendo 299 IES públicas e 2.238 IES privadas, havendo uma predominância das faculdades $(86,2 \%)$ no setor privado, enquanto que no setor público prevalece como maioria as universidades em um percentual de 53,8\%. As IES privadas possuem uma participação de 75,4\% (6.373.274) do total de matrículas em cursos de graduação, enquanto a rede pública participa com 24,6\% (2.077.481). A prevalência do setor privado na oferta do ensino superior com fins lucrativos vem processando-se sob o aporte financeiro do governo federal, a partir de 
incentivos fiscais que favorecem as instituições que aderem ao Programa Universidade para Todos (PROUNI) e Programa de Fundo de Financiamento Estudantil (FIES), ao repassar recursos do fundo público em troca de vagas, constituindo a parceria públicoprivado que se reconfigura em meio a negociação de ações em bolsas de valores na constituição de um aglomerado de instituições nacionais e internacionais (CHAVES, 2010; JEZINE; BITTAR, 2013; MANCEBO, 2017).

O setor público, por sua vez, teve seu boom de expansão a partir do Programa Expandir (2003-2006), que buscou interiorizar as ações das IES públicas, e do Plano de Reestruturação e Expansão das Universidades Federais (REUNI, 2007-2012), com forte vínculo às políticas de ação afirmativas e/ou políticas de reserva de cotas sociais, em que passam a oportunizar acesso ao ensino superior aos sujeitos com histórico de exclusão, como negros, pardos, afrodescendentes, deficientes e outros grupos sociais.

Em que pese o Programa Reuni e as políticas de reserva de vagas, que favoreceram a expansão do acesso e o ingresso de sujeitos com histórico de desigualdade social aos cursos superiores, outros e diferentes processos de exclusão podem conduzir à evasão do curso e do sistema ao longo do processo de permanência e conclusão. Com efeito, a materialidade das condições financeiras para a moradia, alimentação, transporte e material de estudo, como outros elementos básicos, é um fator que pode impedir e/ou dificultar a permanência e o sucesso, entendidos como a conclusão do curso e a inserção no mercado de trabalho (ZAGO, 2006).

Os estudos de Sguissardi (2008, 2015) e Araújo (2016), ao analisarem as políticas de expansão do acesso em suas contradições no contexto da reconfiguração do capitalismo apontam para a necessidade de análise em campos diversos da educação superior, configurando a expansão da educação superior em suas concepções, contradições e desafios. Dentre esses desafios destaca-se, no contexto de expansão associado às políticas de inclusão social, o fenômeno da permanência. De modo que, buscar-se discutir quais fatores que contribuem para a permanência?

Como procedimento metodológico para a análise da problemática adota-se a abordagem qualitativa de pesquisa, em sua tipologia analítica dos dados, em que o locus de investigação são os cursos de Pedagogia e Direito da Universidade Federal da Paraíba (UFPB), tomando como referência o campo relacional de análise assimilados como cursos de baixo e alto prestígio social, respectivamente, e o campo social do status ocupado no exercício da profissão e da escolha pessoal. Parte-se do princípio que há uma valorização e 
desvalorização alcançada no campo do capital cultural, bens simbólicos que se expressam nas escolhas pela formação e na relação do contexto sociocultural do sujeito e do valor pago ao trabalho do profissional (BOURDIEU, 2007).

Sob esta perspectiva teórica, e com o objetivo de compreender quais fatores contribuem para a permanência em cursos superiores, foi aplicada a "Escala para Avaliação da Permanência Discente" (NAKAMURA; CASTELO BRANCO; JEZINE, 2017), composta por dimensões e itens cujas respostas são variáveis nominais, ordinais e escalares, do tipo Likert ${ }^{1}$, com o propósito de mensurar atitudes e comportamentos.

Nesses termos metodológicos, e sob o aporte teórico de Bourdieu a partir das categorias de análise de prestígio social e capital cultural busca-se desvendar sinais de desigualdades sociais que se entrelaçam da escolha do curso ao processo de permanência e conclusão.

\section{O ingresso por políticas de cotas em cursos superiores: o caso da UFPB}

A realidade brasileira está marcada por extremas desigualdades sociais, principalmente relacionadas às condições de acesso aos bens culturais, como a educação e os processos de escolarização. No conjunto dessas desigualdades, ganha relevância a desproporção do nível de escolaridade entre pretos e brancos, fruto do processo de colonização e escravização pelo qual o país passou ao longo de sua história, e em que se enraizou o preconceito a partir da ideia de menor valor a determinado grupo social, como expressa Guimarães (2004, p. 11), para quem o racismo surge no cenário da política brasileira, "como doutrina científica, quando se avizinha à abolição da escravatura e, consequentemente, à igualdade política e formal entre todos os brasileiros, e mesmo entre estes e os africanos escravizados". A diferença entre a "Casa Grande e a Senzala" (Gilberto Freyre) são materializadas nas diferenças entre as escolhas e os escolhidos em diversos âmbitos, do trabalho às dinâmicas sociais e culturais.

Essas diferenças ganham visibilidade a partir dos dados da Síntese de Indicadores Sociais (SIS) do Instituto Brasileiro de Geografia e Estatística que indica.

\footnotetext{
${ }^{1}$ São proposições que buscam verificar o nível de concordância ou discordância do sujeito a partir de uma série de afirmações que expressem algo favorável ou desfavorável em relação ao objeto (CASTELO BRANCO; NAKAMURA; JEZINE, 2017).
} 
Em 2018, 25,2\% dos jovens brasileiros com entre 18 e 24 anos estavam cursando ou já haviam concluído o ensino superior, mas o recorte racial mostra que, considerando apenas a taxa de matrículas de jovens brancos, essa porcentagem salta para 36,1\%. Já olhando apenas para os jovens negros (pretos ou pardos), o índice cai pela metade: 18,3\%. (IBGE, 2019 apud MORENO, 2019, online)

Desses dados, reside a importância de traçar o perfil socioeconômico dos estudantes ingressos por políticas de cotas a partir de um conjunto de variáveis objetivas que podem qualificar o indivíduo ou um grupo social, a fim de mensurar as condições da materialidade para a permanência em cursos superiores. Bourdieu (2015) acentua a dimensão da origem social dos alunos como constituinte das desigualdades escolares que são reproduzidas no interior do sistema, e que, por sua vez, objetiva posições de dominação.

Para Bourdieu (2015), o conceito "capital" na análise social não faz referência apenas à forma econômica, mas sobretudo à forma cultural e social em que os sujeitos se inserem e em que podem receber vantagens a partir do pertencimento ao grupo social. Bourdieu explica que é necessário o capital econômico para o sujeito subsidiar a obtenção de um capital cultural mais elevado, desde que esse pensamento faça parte das estratégias familiares. Sob esta ótica, questiona-se: como permanecer e concluir curso superior com poucos recursos econômicos e sociais?

A origem escolar constitui-se de uma variável importante, como sinalizadora do capital cultural, reconhecido como um conjunto de conhecimentos prévios, ao considerar as artes, como a música, dança, pintura, escultura, teatro, literatura, cinema e fotografia, conhecimentos políticos em geral, sejam nacionais e internacionais, história, geografia, leitura de jornais, revistas, conhecimentos apropriados pelos alunos e que se tornam eficazes na ação pedagógica e/ou sucesso no campo universitário e na manutenção da herança cultural.

Para Bourdieu e Passeron (2007), prevalece a ideia de que a chance de um estudante de classe alta obter o sucesso é maior do que um estudante da classe popular, isso porque o sistema escolar reproduz as desigualdades sociais em seus aspectos familiares, culturais e sociais. A posse do capital cultural contribui para o desempenho escolar na medida em que facilita a aprendizagem dos conteúdos e códigos escolares. A escola não é neutra, as chances são desiguais, alguns estariam numa condição mais favorável do que outros para atender as exigências muitas vezes implícitas da escola. Os “[...] mecanismos de eliminação agem durante todo o cursus, é legítimo apreender o 
efeito desses mecanismos nos graus mais elevados da carreira escolar" (BOURDIEU, 2015, p. 45).

$\mathrm{Na}$ busca de avançar com o debate das problemáticas apontadas por Bourdieu acerca da relação sucesso escolar e desigualdades sociais, Xypas e Santos (2015) entendem que o sucesso escolar de alunos de origem popular explica-se pelo esforço humano.

A tese levantada por Xypas $(2015,2017)$ acerca da potencialidade humana para superação das dificuldades sociais toma expressão a partir do argumento de que "nas sociedades em desenvolvimento como o Brasil, existe, ao lado da reprodução social, outra realidade social: a ascensão social pelos estudos de gente oriunda de classe popular" (XYPAS, 2017, p. 7). De fato, mas são os casos de exceção à regra, como ressalta o autor a partir da sociologia do improvável, em que o elemento atribuído à noção de "vontade própria" diz respeito à percepção das expectativas no indivíduo em relação ao comportamento e ao reforço social. "O sucesso escolar de alunos de origem popular, ou seja, sem capital cultural familiar, depende de ao menos quatro conjuntos de condições: da família; da ação de professores; de condições sociais extraescolares, enfim, da vontade e dos esforços do aluno" (Ibidem, p. 14).

Bergier e Xypas (2013), sob a perspectiva da sociologia do improvável, ao analisar os casos de sucesso de sujeitos com histórico de reprovação e falta de apoio dos pais nos estudos, reforçam a importância da análise das variáveis origem escolar e escolaridade dos pais para a análise da permanência e conclusão do curso. Neste sentido, tais variáveis se constituem de elevada importância, principalmente, no tocante ao ingresso de sujeitos a partir da Lei $\mathrm{N}^{\mathrm{0}} 12.711 / 2012$, que garante a reserva de 50\% das matrículas por curso e turno nas universidades e institutos federais aos alunos oriundos do ensino médio público.

No contexto das desigualdades sociais, a política de reserva de vagas adquire a condição de "reparação social" ao buscar diminuir o flanco entre brancos e negros. De 2016 a 2018, o aumento de negros em cursos superiores foi de 16,2 para 17,8 pontos percentuais, um crescimento de jovens negros em cursos superiores, o que não altera as discrepâncias historicamente construídas. A análise de Santos (apud MORENO, 2019, online), fundador da ONG Educafro, indica que para ocorrer a cota para negros "tivemos que aceitar a cota para a rede pública. E, no Brasil, quem termina prioritariamente o ensino médio são os brancos. Entre os pobres, quem termina prioritariamente o ensino médio são os brancos". 
Considerando essa realidade é possível inferir que as desigualdades de escolarização entre brancos e negros ainda se constitui de uma problemática de desigualdade social, em que pesa a importância das políticas de cotas sociais, pois não se deve perder de vista que tais políticas configuram-se como uma fissura na estrutura histórica elitista e conservadora que ainda persiste nas universidades brasileiras.

No estudo de caso da UFPB, quando se compara o ingresso total por cotas e a ampla concorrência, constata-se que o percentual de ingressos por cotas é menor que o ingresso por ampla concorrência. Dados do período de 2012-2018 assinalam que o total de ingressos é de 71.816, desses, 25.327 são alunos ingressantes por cotas sociais, uma representatividade de $35,27 \%$ frente aos 46.489 , ou seja, $64,73 \%$, que ingressaram por ampla concorrência. Destarte, é possível constatar que não se alcança nessa instituição os $50 \%$ do total de vagas como prevê a Lei de reserva de vagas, ou seja, o direito à vaga destina a grupos sociais de origem da escola pública não se efetiva em sua totalidade, como demonstrado no Gráfico 1.

Gráfico 1 - Número de ingressos por cotas e ampla concorrência na UFPB (2012- 2018)

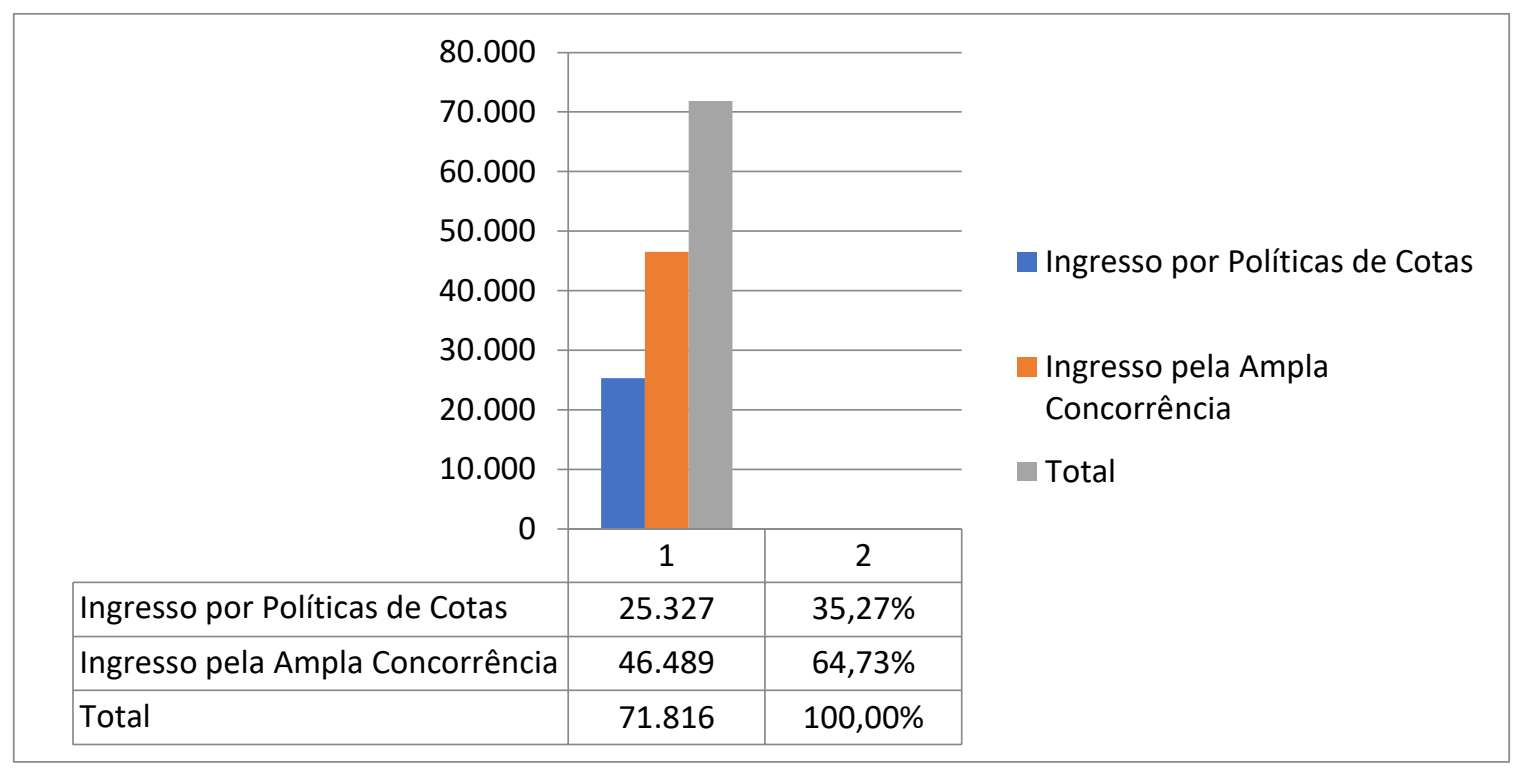

Fonte: Superintendência tecnologia da informação - STI/ UFPB (2018).

É possível caracterizar o perfil socioeconômico, bem como o aumento do número de estudantes na condição de egressos de escola pública, autodeclarados preto e/ou pardo e de baixa renda, de modo a perceber o perfil de quem ingressa em cursos superiores por políticas de cotas. A pesquisa realizada por Jezine, Castelo Branco e Nakamura (2015) indica que o ingresso de estudantes cotistas na UFPB apresentam particularidades 
importantes, havendo uma expressiva e crescente representatividade de estudantes advindos de escola pública em cursos presenciais na universidade a partir da implementação da Modalidade de Ingresso por Reserva de Vagas (MIRV - 2011) e, posteriormente as políticas de cotas, regulamentada pela Lei ${ }^{\circ}$ 12.711/2012.

Dos ingressos por políticas de cotas, no período de 2012 a 2018, é possível perceber as diferenças na caracterização do perfil socioeconômico, havendo paulatinamente, um aumento do número de ingressos de origem de escola pública, como se pode constatar no Quadro 1.

Quadro 1 - Perfil Socioeconômico de estudantes ingressos por políticas de cotas na UFPB (2012-2018)

\begin{tabular}{|c|c|c|c|c|c|c|c|}
\hline PERFIS DOS INGRESSANTES COTISTAS NA UFPB & 2012 & 2013 & 2014 & 2015 & 2016 & 2017 & 2018 \\
\hline $\begin{array}{l}\text { Candidato autodeclarado preto ou pardo egresso do ensino público } \\
\text { que cursou pelo menos três anos do ensino fundamental e todo o } \\
\text { ensino médio em escolas públicas. }\end{array}$ & 284 & 8 & & & & & \\
\hline Candidato preto ou pardo, egresso do ensino público. & 955 & 11 & & & & & \\
\hline $\begin{array}{l}\text { Candidatos autodeclarados pretos ou pardos que, } \\
\text { independentemente da renda (art. } 14, \mathrm{II} \text {, Portaria Normativa } \mathrm{n}^{\circ} \\
18 / 2012 \text { ), tenham cursado integralmente o ensino médio em } \\
\text { escolas. }\end{array}$ & & & 19 & & & & \\
\hline $\begin{array}{l}\text { Candidatos autodeclarados pretos ou pardos, com renda familiar } \\
\text { bruta per capita igual ou inferior a } 1,5 \text { salário mínimo que tenham } \\
\text { cursado integralmente o ensino médio em escolas públicas (Lei } n^{\circ} \\
12.711 / 2012) \text {. }\end{array}$ & & & 25 & & & & \\
\hline Candidato indígena, egresso do ensino público. & 60 & & 7 & & & & \\
\hline $\begin{array}{l}\text { Candidatos autodeclarados indígenas que, independentemente da } \\
\text { renda (art. } 14, \mathrm{II} \text {, Portaria Normativa } n^{\circ} 18 / 2012 \text { ), tenham cursado } \\
\text { integralmente o ensino médio em escolas públicas. }\end{array}$ & & & 5 & & & & \\
\hline $\begin{array}{l}\text { Ingressante de escola pública que se autodeclara pardo, preto ou } \\
\text { indígena. }\end{array}$ & & 725 & 936 & 941 & 1372 & 1600 & \\
\hline Candidato egresso do ensino público. & 768 & 463 & 559 & 490 & 766 & 915 & 581 \\
\hline $\begin{array}{l}\text { Candidato egresso do ensino público que cursou pelo menos três } \\
\text { anos do ensino fundamental e todo o ensino médio em escolas } \\
\text { públicas. }\end{array}$ & 230 & 1 & & & & & \\
\hline $\begin{array}{l}\text { Ingressante de escola pública com renda igual ou inferior a 1,5 } \\
\text { salário mínimo. }\end{array}$ & & 560 & 607 & 474 & 796 & 1108 & 623 \\
\hline $\begin{array}{l}\text { Ingressante de escola pública com renda igual ou inferior a 1,5 } \\
\text { salário mínimo que se autodeclara pardo, preto ou indígena. }\end{array}$ & & 1088 & 1061 & 874 & 1318 & 1805 & 994 \\
\hline Candidato portador de deficiência, egresso do ensino público. & 24 & 30 & 8 & 1 & & 5 & 132 \\
\hline Candidatos com deficiência. & & & 171 & 155 & 168 & 147 & \\
\hline $\begin{array}{l}\text { Ingressante de escola pública com deficiência e renda igual ou } \\
\text { inferior a } 1,5 \text { salário mínimo que se autodeclara pardo, preto ou } \\
\text { indígena. }\end{array}$ & & & & & & 15 & 14 \\
\hline $\begin{array}{l}\text { Ingressante de escola pública com deficiência que se autodeclara } \\
\text { pardo, preto ou indígena. }\end{array}$ & & & & & & 6 & 147 \\
\hline $\begin{array}{l}\text { Ingressante de escola pública com deficiência e renda igual ou } \\
\text { inferior a } 1,5 \text { salário mínimo. }\end{array}$ & & & & & & 18 & 106 \\
\hline Surdos & & & & & & 17 & \\
\hline TOTAL DE INGRESSANTES ATRAVES DO SISTE & 2321 & 2886 & 3398 & 2935 & 4420 & 5636 & 1375 \\
\hline
\end{tabular}

Fonte: Superintendência de Tecnologia da Informação - STI / UFPB (2018). Atualizado a partir de Macedo (2017)

Os dados dos ingressos por políticas de cotas indicam maior número no ano de 2017, em que se registra 5.636 alunos, havendo uma diminuição em 2018, 3.731 alunos. Os dados demonstram o alcance da política de expansão no que se refere ao acesso de um público com características peculiares, tendo maior relevância os ingressantes advindos de 
escola pública, que em geral possuem também a característica de menor renda e diferença étnico-racial, ou seja, com renda igual ou inferior a 1,5 salário mínimo e autodeclaração de negro, pardo ou indígena. No ano de 2012 registrou-se o total de 2.321 estudantes ingressos por políticas de cotas. Em 2015 vê-se um tímido crescimento da quantidade de discentes cotistas na referida instituição, com o ingresso de 2.935, subindo em 2018 para 3.731 .

Na comparação entre o ingresso por políticas de cotas e por ampla concorrência (Gráfico 1), observando-se o perfil socioeconômico (Quadro 1), constata-se que o critério origem escola pública em sua maioria associa-se aos sujeitos autodeclarados negros e/ou pardos; de modo que o atributo classe social e renda mantém íntima relação com as questões étnico-raciais. Nesse sentido, como se explica o não preenchimento dos $50 \%$ das vagas garantidos pela Lei?

É possível supor que os estudantes advindos de escolas públicas, com a caracterização de baixa renda, pais com baixa escolaridade e pertencentes aos grupos étnico-raciais, não têm conhecimento acerca do processo de ingresso ao ensino superior; que eles não possuem interesse em cursar o nível superior devido ao imaginário de que o acesso à universidade é algo distante de sua realidade cultural; que se sintam despreparados para um processo seletivo que envolve vários campos de disputas; que precisem ingressar no mercado de trabalho ou mesmo entendam que a formação superior não oferece possibilidades concretas de trabalho; que estejam conformados com sua condição social e cultural. Tais hipóteses necessitam de investigação a fim de que se possa verificar os argumentos sobre a importância da política de cotas como uma condição de reparação e justiça social para uma população que historicamente não teve igualdade de oportunidade. Nesse conjunto, constata-se o distanciamento entre os anos de escolaridade entre brancos e negros, o que contribui para a ampliação das desigualdades sociais.

Entre 2016 e 2018, na população preta ou parda, a taxa de analfabetismo das pessoas de 15 anos ou mais de idade passou de $9,8 \%$ para $9,1 \%$, e a proporção de pessoas de 25 anos ou mais de idade com pelo menos o ensino médio completo se ampliou de $37,3 \%$ para 40,3\%. Ambos os indicadores, porém, permaneceram aquém dos observados na população branca, cuja taxa de analfabetismo era $3,9 \%$, e a proporção de pessoas com pelo menos o ensino médio completo era $55,8 \%$, considerando os mesmos grupos etários mencionados, em 2018 (IBGE, 2019).

Os dados nos conduzem a inferir que a conjunção das políticas de expansão às 
políticas de cotas favorece o ingresso de sujeitos em condição de desigualdade social e que a permanência em cursos superiores de sujeitos com tais características constitui-se uma pauta de debate urgente para o processo de formação acadêmica e sucesso universitário.

\section{Fatores que favorecem a permanência em cursos superiores de alto e baixo prestígio social}

A problemática da permanência de estudantes por políticas de cotas toma outras conotações quando se passa a analisar o ingresso em cursos superiores na relação com outras variáveis, tais como: cursos de alto e baixo prestígio social. Assim, na busca de compreender o processo de permanência de sujeitos ingressos por políticas de cotas em cursos considerados de alto e baixo prestígio social foi aplicada a Escala para Avaliação da Permanência Discente (NAKAMURA; CASTELO BRANCO; JEZINE, 2017).

A partir das questões da Escala buscou-se "verificar o nível de concordância do sujeito com uma série de afirmações que expressem algo favorável ou desfavorável em relação a um objeto psicológico" (LIKERT, 1976 apud SANCHES; MEIRELES; DI SORDI, 2011, p. 2), tornando possível traçar o perfil socioeconômico dos ingressantes por políticas de cotas nos cursos de Direito e Pedagogia da UFPB.

Para a composição do perfil do estudante dentre as variáveis constantes na Escala (CASTELO BRANCO; NAKAMURA; JEZINE, 2017) adotou-se as seguintes variáveis: renda total familiar, tipo de escola do ensino fundamental e médio que frequentou e, no que refere-se a dimensão da permanência, buscou-se compreender os fatores institucionais que contribuem para a permanência.

Ao se analisar o ingresso a partir do Sistema de Seleção Unificada ( $\mathrm{SiSu}$ ) nos cursos presenciais da UFPB de Direitos e Pedagogia, no período de 2012 a 2016, constatase que ingressaram 712 alunos no curso de Pedagogia e 776 alunos no curso de Direito, totalizando 1.488 alunos, sendo 387 estudantes ativos, ativos-formando e concluintes, compondo um percentual de 54,35 de permanência no curso de Pedagogia; e, no curso de Direito, dos 776 alunos ingressantes, 421 são ativos, ativos-formando e concluintes, um percentual de 54,25, conforme o Gráfico 2.

Gráfico 2 - Ingressos por Políticas de Cotas nos cursos de Pedagogia e Direito 2012-2016 


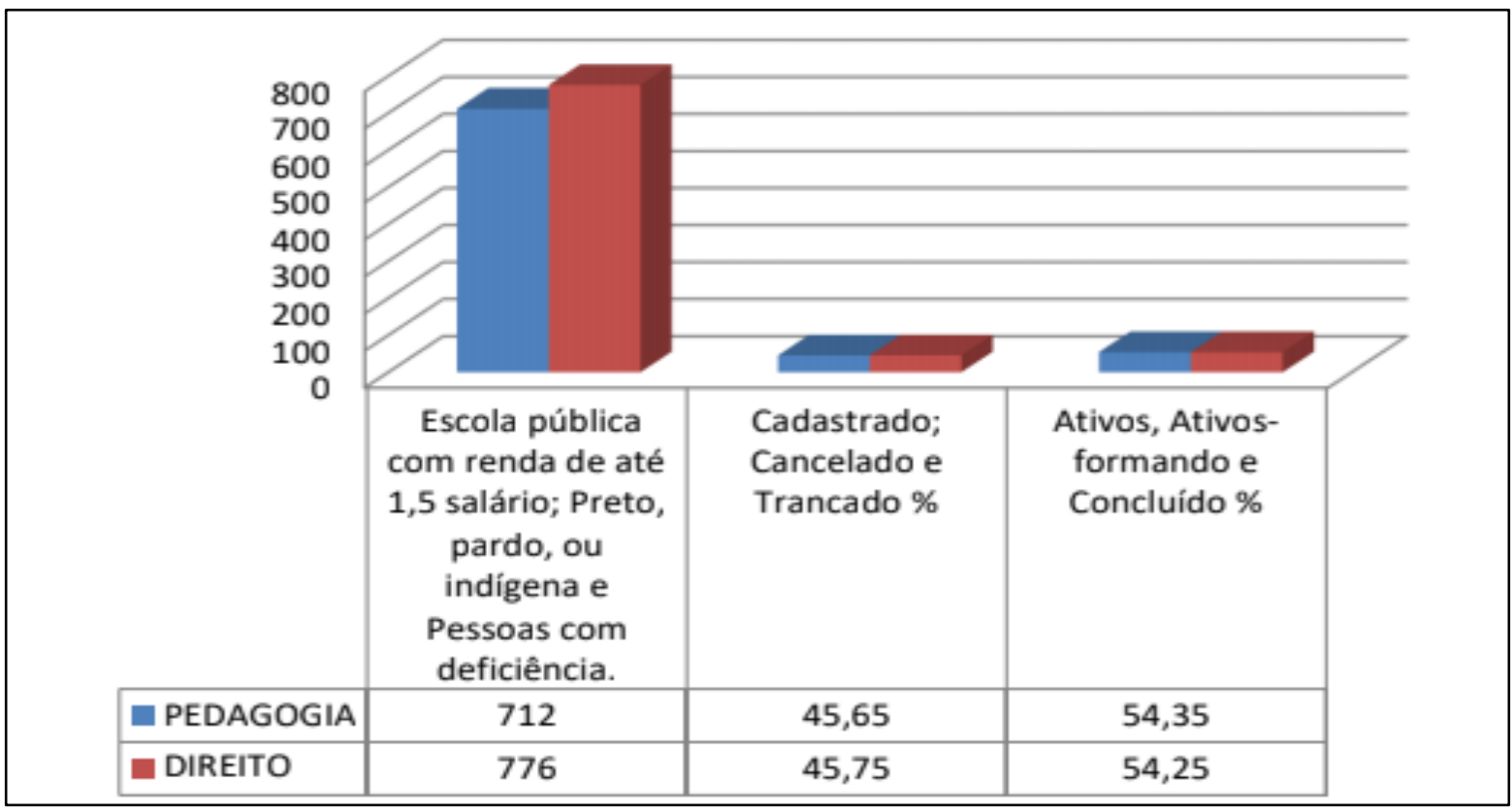

Fonte: Superintendência de Tecnologia da Informação - STI / UFPB (2016).

Embora, o total de alunos ingressos por políticas de cotas sociais na instituição, no período de 2012 a 2018, ter apresentado um percentual menor que 50\% (Gráfico 1), ao se analisar os ingressos nos cursos Pedagogia e Direito, os estudantes que mantêm-se ativos, ativos-formando e concluintes, no ciclo de estudo dos cursos pesquisados, os dados demonstram que há representatividade positiva de estudantes ingressantes pelas políticas de cotas em uma percentagem de mais de 50\%. Nesse ínterim, a Lei de cotas sociais, vivenciada nas instituições públicas federais de ensino superior, atingiu o objetivo, ao reconhecer o direito à diferença de tratamento legal para grupos que sofreram (e sofrem) discriminação de raça e classe, oferecendo-lhes oportunidade de ingresso e conclusão em cursos superiores.

No caso em destaque, os cursos de Direito e Pedagogia não apresentam discrepâncias no processo de conclusão, embora o curso de Direito carregue a predominância do status social de Bacharel, de maior valor no mercado profissional, e o curso de Pedagogia, como uma Licenciatura, a prerrogativa de formação de docentes para atuar na educação básica, uma menor status social e profissional. Todavia, enquanto o primeiro curso firma a ideia do filho doutor advogado, o segundo garante a conclusão do curso superior com um mercado de trabalho mais ampliado.

Nesse sentido, é mister traçar o perfil socioeconômico dos ingressos pré-concluinte e concluintes, a partir de um conjunto de variáveis que qualifica o indivíduo em seu grupo social, nível socioeconômico e capital cultural, pois conforme Bourdieu (2015), o 
indivíduo é socialmente constituído a partir de sua formação inicial, no ambiente social e familiar, sendo que a incorporação de um conjunto de dispositivos que o tipifica passa a se constituir um habitus familiar ou de classe, conduzindo o sujeito ao longo do tempo, correspondente à posição que tenderia a ocupar na estrutura social.

Para tanto, a Escala para Avaliação da Permanência Discente foi aplicada presencialmente a 40 estudantes pré-concluintes e concluintes dos cursos Pedagogia e Direito. Especificamente, 20 alunos do curso de Pedagogia, turnos manhã, tarde e noite, e 20 do curso de Direito, turnos manhã e noite do Campus I da UFPB. Os sujeitos responderam a Escala no período de 02 a 13 de abril de 2018, em que o objetivo foi reconhecer as características que possam constituir o perfil socioeconômico dos estudantes pré e concluintes que permaneceram nos cursos com sucesso, ou seja, encontram-se na fase de conclusão, conforme Gráfico 3.

Gráfico 3 - Renda total mensal da família dos estudantes concluintes dos cursos de Pedagogia e Direito UFPB

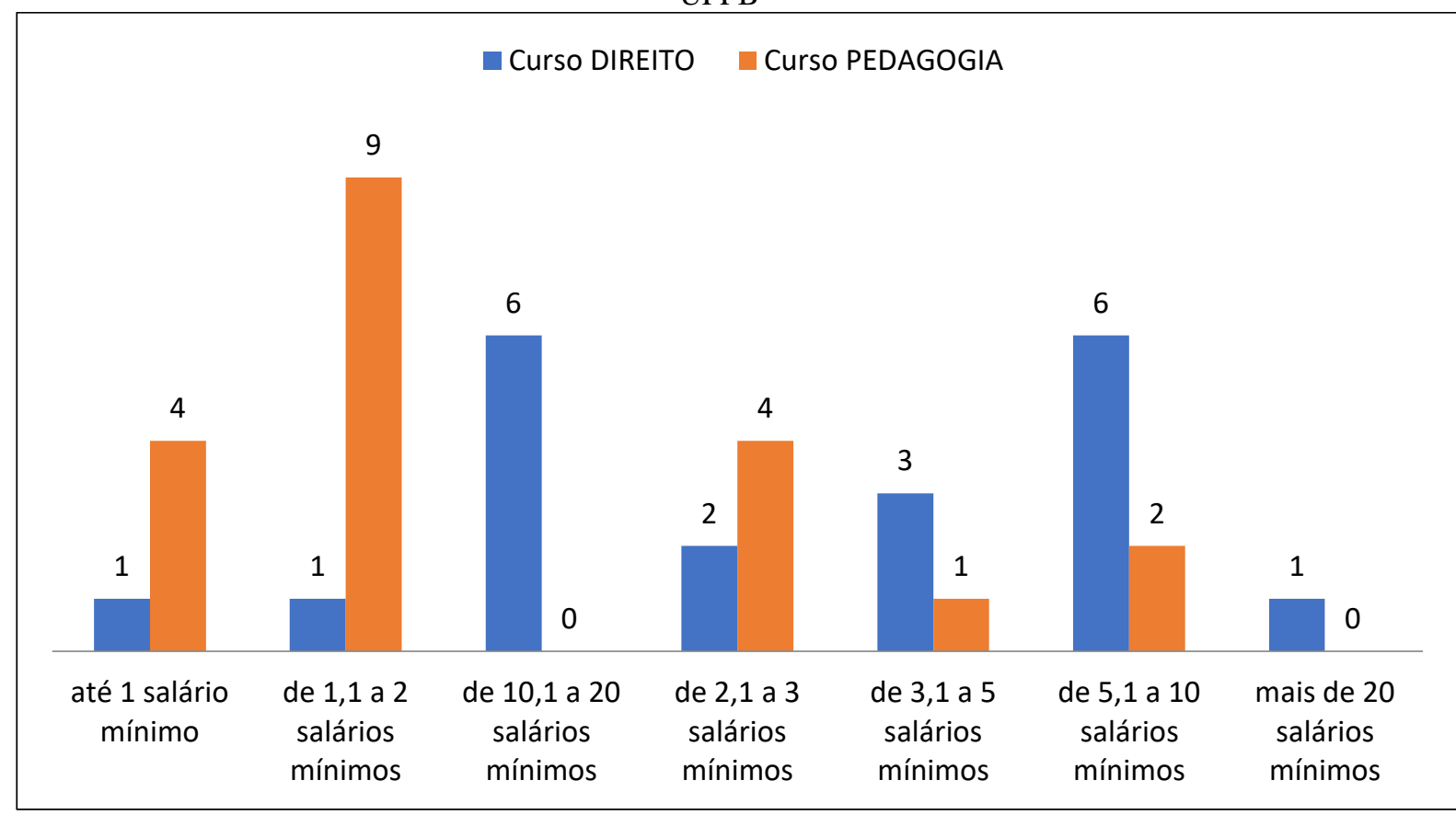

Fonte: Escala aplicada aos concluintes e pré-concluintes do curso de Direito e Pedagogia.

A renda familiar, conforme o Gráfico 3, é diferente entre os cursos. No curso de Direito há predominância de estudantes com renda familiar acima de 3 salários mínimos enquanto que no curso de Pedagogia há predominância da renda familiar de 1 a 3 salários mínimos. Para Bourdieu (1983, p. 72), “cada agente, quer ele saiba ou não, quer ele queira ou não, é produtor e reprodutor de sentido objetivo: porque suas ações e suas obras são o 
produto de um 'modus operandi' do qual ele não é o produtor e do qual não tem o domínio consciente", daí a importância do sujeito e seus familiares subsidiarem a elevação do capital cultural por via do capital econômico.

Na sequência da relação entre o perfil socioeconômico e a permanência em cursos de baixo e alto prestígio social, a origem escolar torna-se um dado importante porque se constitui um requisito para o acesso a partir das políticas de inclusão social, como pode se constituir em um sinalizador do capital cultural, reconhecido como um conjunto de conhecimentos prévios, que possibilitam a aspiração social cultural, bem como a materialidade da existência.

Gráfico 4 - Tipos de escola de ensino fundamental dos pré e concluintes dos cursos de Pedagogia e Direito/UFPB

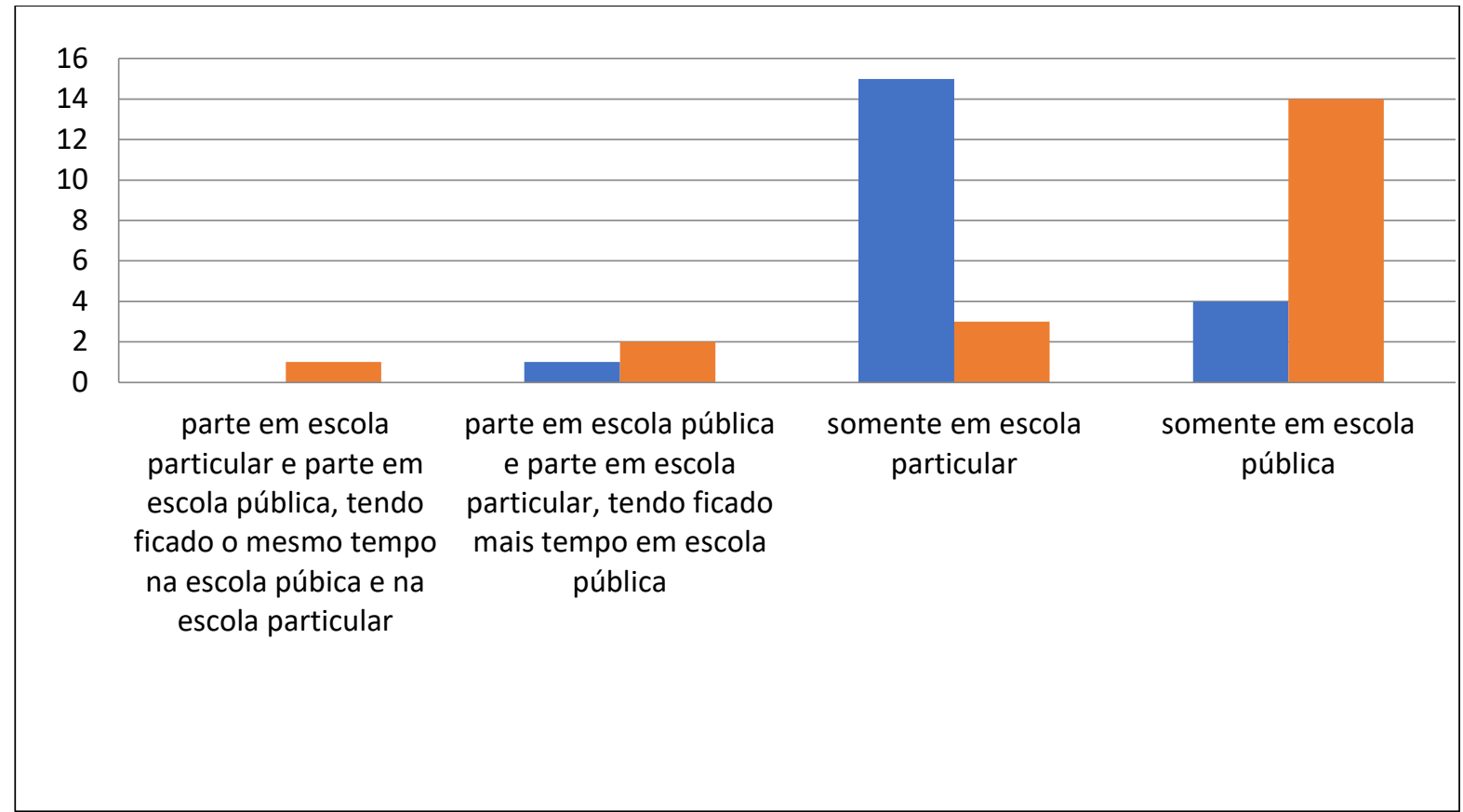

Fonte: Escala aplicada aos concluintes e pré-concluintes do curso de Direito e Pedagogia.

Com relação a origem do ensino educacional apontada no Gráfico 4, constata-se que a maioria dos estudantes do curso de Pedagogia advém do ensino fundamental de escolas públicas. Por seu turno, no curso de Direito são predominantes os estudantes advindos de escola de ensino fundamental particular, o que demanda a aquisição do capital cultural adquirido ao nível de maior representatividade das condições de acesso ao conhecimento cultural elaborado.

Tais traços históricos de formação demandam uma diferenciação na estruturação das aquisições escolares. O mesmo fato se repete com relação ao tipo de escola de ensino médio, em que segue a mesma disparidade do ensino fundamental, ou seja, a maioria dos 
estudantes do curso de Pedagogia se origina da escola pública e, os estudantes do curso de Direito, da escola particular, como se pode observar no Gráfico 5.

Gráfico 5 - Tipos de escola de ensino médio dos pré e concluintes dos cursos Pedagogia e Direito/UFPB

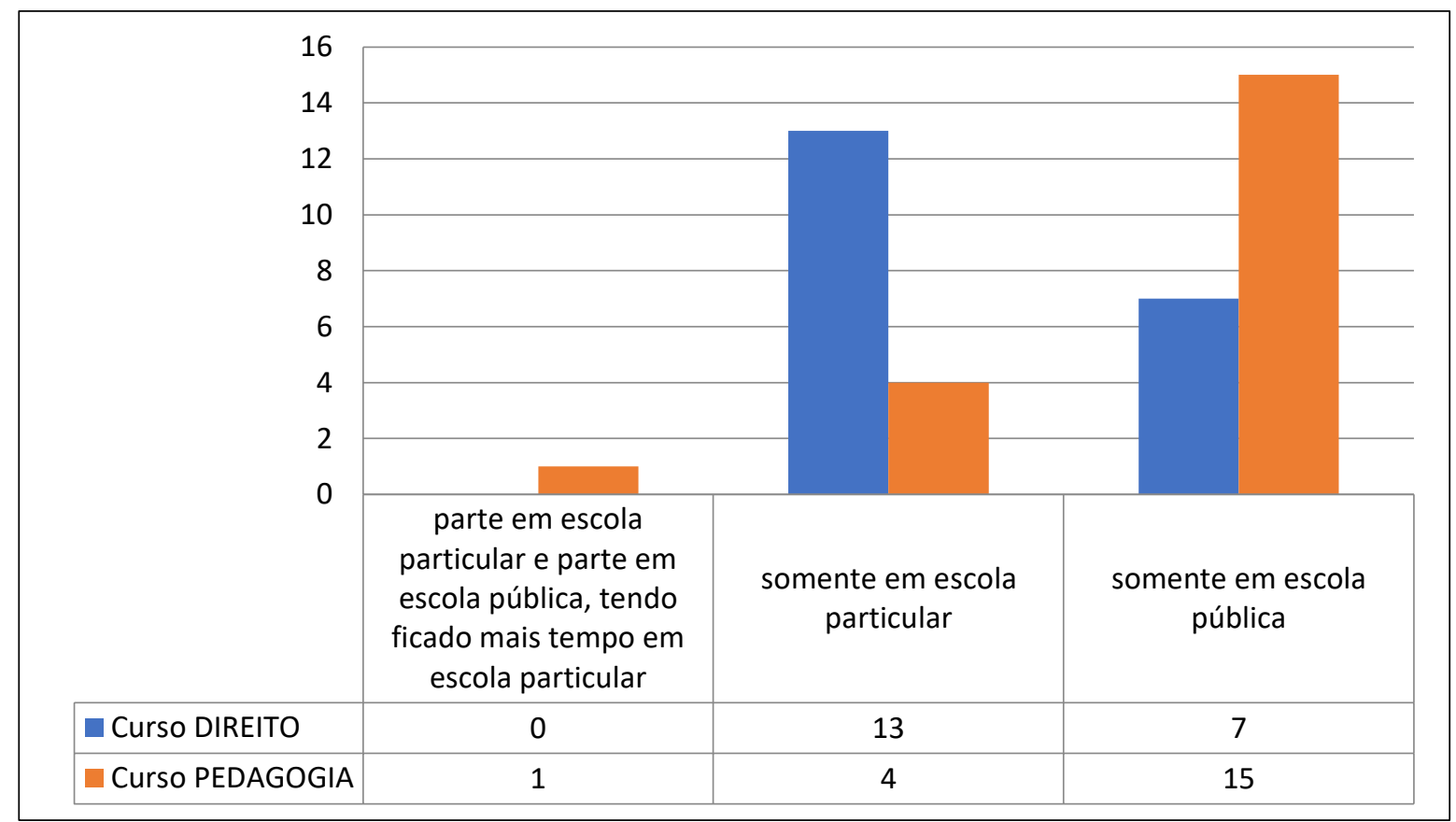

Fonte: Escala aplicada aos concluintes e pré-concluintes do curso de Direito e Pedagogia.

Assim, dos 20 respondentes do curso de Pedagogia, 15 (quinze) estudaram em escola pública e 4 (quatro) em escola particular. Os dados indicam que os estudantes pré e concluintes do curso de Pedagogia ingressaram no curso com menor capital cultural, devido a maioria ser advinda de escolas públicas. Ao contrário, dos estudantes do curso de Direito que do total de 20 respondentes, 13 (treze) estudaram em escola particular e 7 (sete) em escola pública, o que, por sua vez, supõe-se que esses ingressos deram início ao curso com maior capital cultural, com maior renda familiar, ou seja, sob melhores condições para a permanência e conclusão do curso.

Os aspectos econômicos demonstrados por meios dos gráficos, no que se refere a renda familiar, possui forte influência ao acesso dos sujeitos aos espaços culturais e educacionais. É notório o acesso anterior dos alunos do curso de Direito ao ensino particular, tanto no Ensino Fundamental, quanto no Médio, indicando, ao menos teoricamente, que os ingressantes no curso de Direito a priori chegam ao curso com uma melhor base de capital cultural que e os estudantes do curso de Pedagogia. $\mathrm{O}$ fato indica que a permanência se constitui uma problemática aos estudantes em contexto de 
desigualdade social, o que demanda políticas institucionais de acompanhamento e apoio para a conclusão do curso.

A pesquisa "Políticas de Acesso à Educação Superior e os desafios da Inclusão Social” realizada por de Jezine, Castelo Branco e Nakamura (2015) constata que os grupos sociais que se encontram em situação de desigualdade social, com renda de 1 a 3 salários mínimos, oriundos de escola pública, autodeclarados pardos ou negros e com pais com baixa escolaridade, aumentam sua proporção na instituição a partir da implementação das políticas de inclusão social. De modo que, compreender os fatores que podem contribuir para que estes estudantes consigam superar a barreira da exclusão e da evasão do curso superior, torna-se uma urgência para a estruturação de políticas de permanência e minimização dos processos de evasão e retenção.

E, com relação a dimensão permanência, os dados foram obtidos por meio da aplicação da Escala, como demonstrado no Quadro 2. É perceptível que os fatores institucionais, como a implantação de programas de assistência/financiamento estudantil nos cursos de Pedagogia e Direito, não tem relevância para a permanência, pois $75 \%$ dos estudantes de Pedagogia e $80 \%$ dos estudantes de Direito discordam parcialmente/totalmente, o que significa que eles continuam e concluem o curso independente de encontrarem-se inseridos em Programas de Assistência Estudantil, como se pode analisar no quadro 2 .

Quadro 2 - Fatores institucionais que contribuem para a permanência em cursos de Direito e Pedagogia alunos pré concluintes e concluintes.

\begin{tabular}{|l|c|c|c|c|}
\hline \multicolumn{2}{|c|}{$\begin{array}{c}\text { Dimensão de Permanência } \\
20 \begin{array}{c}\text { alunos do curso de Pedagogia e 20 do curso de } \\
\text { Direito - Pré-concluintes e concluintes }\end{array}\end{array}$} & \multicolumn{2}{c|}{ DP DT* CT* } \\
\cline { 2 - 5 } & Pedagogia & Direito & Pedagogia & Direito \\
\hline $\begin{array}{l}\text { Eu continuo no curso porque a família ajuda. } \\
\text { Eu continuo no curso porque estou num programa } \\
\text { acadêmico de bolsas de estudo. }\end{array}$ & $70 \%$ & $\mathbf{9 0 \%}$ & $20 \%$ & $5 \%$ \\
\hline $\begin{array}{l}\text { Eu continuo no curso porque estou inserido no } \\
\text { programa de assistência estudantil. }\end{array}$ & $\mathbf{7 5 \%}$ & $\mathbf{8 0 \%}$ & $15 \%$ & $5 \%$ \\
\hline $\begin{array}{l}\text { Eu continuo no curso porque me proporciona boa } \\
\text { perspectiva profissional }\end{array}$ & $25 \%$ & $10 \%$ & $\mathbf{7 5 \%}$ & $\mathbf{9 0 \%}$ \\
\hline $\begin{array}{l}\text { Eu continuo no curso porque proporcionará minha } \\
\text { ascensão social }\end{array}$ & $60 \%$ & $25 \%$ & $40 \%$ & $\mathbf{7 5 \%}$ \\
\hline $\begin{array}{l}\text { Os professores do curso motivam o aluno a } \\
\text { permanecer e concluir o curso. }\end{array}$ & $40 \%$ & $75 \%$ & $\mathbf{6 0 \%}$ & $\mathbf{2 5 \%}$ \\
\hline
\end{tabular}




\begin{tabular}{|l|c|c|c|c|}
\hline De maneira geral, eu estou satisfeito com o curso & $15 \%$ & $40 \%$ & $\mathbf{8 5 \%}$ & $\mathbf{6 0 \%}$ \\
\hline
\end{tabular}

Fonte: Questionário aplicado aos concluintes e pré-concluintes do curso de Direito e Pedagogia.

*DP DT - Discordo Parcialmente, Discordo Totalmente; CP CT - Concordo Parcialmente, Concordo

Totalmente.

De modo geral, os resultados contrariam a premissa de que "faz-se Pedagogia porque foi o que deu!", uma vez que pontam que os alunos de Pedagogia se encontram satisfeitos com o curso, na razão de $85 \%$, e os do Curso de Direito estão parcialmente satisfeitos, na razão de $60 \%$.

Um dado relevante para pensar a permanência diz respeito à perspectiva profissional em ambos os cursos: os sujeitos, em um total de $75 \%$ e $90 \%$ dos cursos de Direito e Pedagogia, respectivamente, são favoráveis ao curso em relação à empregabilidade no mercado profissional. A avaliação dos estudantes concluintes e préconcluintes em relação aos cursos pesquisados é parcialmente positiva, uns pela identificação com o curso (Pedagogia), outros por seu alto prestígio social (Direito).

Com relação aos aspectos econômicos, a pesquisa demonstra que a renda familiar influencia no acesso dos sujeitos aos cursos de alto prestígio social. $\mathrm{O}$ acesso aos bens culturais, desde a família a partir do processo de escolarização, do Ensino Fundamental ao Médio, demonstra, teoricamente, que esses fatores favorecem as condições de ingresso em cursos considerado de maior status social, tanto no mercado como na sociedade. Confirma-se a hipótese que o perfil socioeconômico possui relação como os processos de permanência, pois os ingressantes do curso de Direito constituem-se como maior capital cultural do que os do curso de Pedagogia, mesmo os que estão na condição de menor renda e advindos de escola pública encontram-se no grupo de brancos, que em sua maioria concluem mais o ensino médio, o que indica que há um relação díspar entre escolaridade e raça, como já assinalado.

Embora os dados indiquem que as políticas de assistência estudantil pouco contribuem para a permanência, não se pode negar a contribuição desses programas para a permanência dos estudantes, principalmente os ingressantes por políticas de cotas em cursos de ensino superior. Nesse sentido, Macedo (2017) aponta que as ações de assistência estudantil possibilitam o êxito nas obrigações acadêmicas de estudantes em vulnerabilidade socioeconômica, com reflexo nos índices de aprovação. No caso da UFPB, a pesquisa apresenta dados que revelam que os discentes atendidos pelo Programa Nacional de Assistência Estudantil (PNAES) têm permanecido e concluído o curso de 
graduação. Fato também constatado na pesquisa realizada Souza e Silveira (2016, p. 114) que investigou " [...] se o bolsista teria condições de permanecer na UFPR sem o apoio da política de assistência estudantil" e a maioria dos estudantes que participou da pesquisa afirma: "que não teria condições de permanecer na instituição sem o apoio da política de assistência estudantil".

\section{CONSIDERAÇÕES FINAIS}

A complexidade e contradição da temática permanência de sujeitos em contexto de desigualdade social em cursos superiores, não nos permite uma análise conclusiva, todavia, os dados são reveladores das dinâmicas de desigualdades sociais construídas ao longo da história da humanidade e que se propagam como ideologias. Embora tenhamos as políticas de reparação social, ainda perdura a ideia de que "curso de Direito não é para pobre", ou mesmo "pobre quando entra na universidade faz Pedagogia". Todavia, um elemento revelador da pesquisa é a satisfação na realização do curso dos sujeitos que estudam Pedagogia. Possivelmente teremos profissionais da educação mais realizados com a profissão, do que advogados, de modo que a formulação é um indicativo para novas investigações.

Desta feita, constata-se que o perfil socioeconômico dos sujeitos ingressos interfere no processo de permanência e conclusão do curso, pois embora o percentual de conclusão nos dois cursos seja equivalente, há uma diferença nas características socioculturais dos sujeitos que permanecem no curso que escolhem, ou seja, curso de Pedagogia considerado de baixo prestígio social para aos que possuem menor renda, pais de baixa escolaridade, e são em sua maioria advindos de escola pública, por outro lado, cursos de Direito com status de alto prestígio social destina-se aos que possuem maior renda familiar, escolaridade e oportunidades de acesso aos bens culturais. Possivelmente tenhamos que concordar com Xypas (2017) quando assinala a existência de uma dose de boa vontade e apoio familiar dos sujeitos para a superação das desigualdades sociais.

Ademais, é possível inferir que as políticas de cotas mudam a cara da universidade, todavia, novos e diferentes processos de exclusão social se constituem, pois a razão do valor do curso na sociedade ainda perdura e se perpétua no imaginário dos sujeitos que desejam manter o status social familiar e daqueles que poucos se atrevem à disputa da dinâmica concorrência desigual. Desta forma, para os que conseguem romper a linha do acesso à universidade e aos cursos considerados de alto prestígio social é preciso garantirlhes a permanência e o sucesso com a conclusão, o que merece estudos mais aprofundados 
acerca da relação permanência e sucesso, bem como do desempenho de sujeitos cotistas.

Com efeito, ressalta-se a importância de aprofundar as discussões acerca das políticas de permanência no ensino superior, no contexto das desigualdades sociais, para uma melhor apreensão da problemática da permanência e sua relação com a política de assistência estudantil.

\section{REFERÊNCIAS}

ARAÚJO, R. S. de. Expansão do ensino superior e desenvolvimentismo: limites e contradições sob a hegemonia do capital. Educação \& Fronteiras On-Line, Dourados MS, v. 6, n. 6, 2016, p. 93 - 105. Disponível em: http://ojs.ufgd.edu.br/index.php/educacao/article/view/5713. Acesso em: 28 de jul. de 2019.

BERGIER, B.; XYPAS C. Para uma sociologia do improvável. Percursos atípicos e sucessos inesperáveis na escola francesa. Revista Educação em Questão, v. 47, n. 33, p. 36-58, set./dez. 2013. Disponível em:

https://periodicos.ufrn.br/educacaoemquestao/article/view/5133. Acesso em: 24 fev. 2019.

BOURDIEU, P. A economia das trocas simbólicas. São Paulo: Perspectivas, 2007.

BOURDIEU, P. Esboço de uma Teoria da Prática. In: ORTIZ, R. (org.). Sociologia. São Paulo: Ática, 1983.

BOURDIEU, P. Escritos de Educação. 16ª ed. Petrópolis: Vozes, 2015.

BOURDIEU, P.; PASSERON J. C. A reprodução: elementos para uma teoria do sistema de ensino (1978). Lisboa: Editorial Veja, 2007.

BRASIL. Instituto Nacional de Estudos e Pesquisas Educacionais Anísio Teixeira (Inep). Censo da Educação Superior 2018: notas estatísticas. Brasília, 2019. Disponível em: http://download.inep.gov.br/educacao_superior/censo_superior/documentos/2019/censo_d a_educacao_superior_2018-notas_estatisticas.pdf_. Acesso em: 23 jan. 2019.

BRASIL. Ministério da Educação. Lei $n^{o} 12.711$, de 29 de agosto de 2012. Dispõe sobre o ingresso nas universidades federais e nas instituições federais de ensino técnico de nível médio e dá outras providências. Brasília, 2012. Disponível em: http://www.planalto.gov.br/ccivil_03/_ato2011-2014/2012/lei/l12711.htm. Acesso em: 03 maio 2019.

BRASIL. Presidência da República. Decreto $n^{\circ}$ 6.096, de 24 de abriu de 2007. Institui o Programa de Apoio a Planos de Reestruturação e Expansão das Universidades Federais REUNI. Brasília: 2012. Disponível em: http://www.planalto.gov.br/ccivil_03/_ato20112014/2012/lei/112711.htm. Acesso em: 03 maio 2019.

BRASIL. Presidência da República. Decreto $n^{\circ} 7.234$, de 19 de julho de 2010. Dispõe sobre o Programa Nacional de Assistência Estudantil-PNAES. Brasília, 2010. Disponível 
em: www.planalto.gov.br/ccivil_03/_Ato2007-2010/2010/Decreto/ D7234.htm. Acesso em: 07 jul. 2019.

BRASIL. Presidência da República. Lei no 9.394, de 20 de dezembro de1996. Lei de Diretrizes e Bases da Educação Nacional - LDBEN. Brasília, 1996. Disponível em: http://www.planalto.gov.br/ccivil_03/leis/19394.htm. Acesso em: 29 jan. 2019.

CASTELO BRANCO, U. V.; NAKAMURA, P. H.; JEZINE, E. Permanência na educação superior no Brasil: construção de uma escala de medida. Revista de la Asociación de Sociología de la Educación (RASE), v. 10, n. 2, p. 209-229, 2017. Disponível em: https://www.researchgate.net/journal/1988-7302_RASE-

Revista_de_la_Asociacion_de_Sociologia_de_la_Educacion Acesso em: 23 jan. 2019

CHAVES, V. L. J. Expansão da privatização/mercantilização do ensino superior Brasileiro: a formação dos oligopólios. Educação e Sociedade. Campinas, v. 31, n.111, abr./jun., 2010. Disponível em: http://www.scielo.br/scielo.php?pid=S010173302010000200010\&script=sci_abstract\&tlng=pt Acesso em: 23 jan. 2019.

GUIMARÃES, A. S. A. Preconceito de cor e racismo no Brasil. Revista de Antropologia, v.47, no.1, São Paulo, 2004. Disponível em:

www.scielo.br/scielo.php?script=sci_arttext\&pid=S0034-77012004000100001. Acesso em: 23 fev. 2019.

INSTITUTO BRASILEIRO DE GEOGRAFIA E ESTATÍSTICA. Estudos e Pesquisas. Informação Demográfica e Socioeconômica. Rio de Janeiro, n. 41, 2019. Disponível em: https://biblioteca.ibge.gov.br/visualizacao/livros/liv101681_informativo.pdf. Acesso em: 25 jan. 2019.

JEZINE, E.; BITTAR, M. Políticas de Educação Superior no Brasil: expansão, acesso e igualdade social. João Pessoa: Editora da UFPB, 2013.

JEZINE, E.; CASTELO BRANCO, U.; NAKAMURA, P. Políticas de Acesso à Educação Superior e os desafios da Inclusão Social. João Pessoa. Editora da UFPB, 2015.

MACEDO, G. D. A Eficácia do Programa de Assistência Estudantil (PNAES) para Permanência dos Ingressantes do Sistema de Cotas na UFPB. Dissertação (Mestrado em Educação). Centro de Educação. Universidade Federal da Paraíba, João Pessoa, 2017.

MORENO, Ana Carolina. Taxa de jovens negros no ensino superior avança, mas ainda é metade da taxa dos brancos. G1 Educação, 2019. Disponível em:

https://g1.globo.com/educacao/noticia/2019/11/06/taxa-de-jovens-negros-no-ensinosuperior-avanca-mas-ainda-e-metade-da-taxa-dos-brancos.ghtml. Acesso em: 23 jan. 2019.

SANCHES, C.; MEIRELES, M.; DE SORDI, J. O. Análise Qualitativa Por Meio da Lógica Paraconsistente: Método de Interpretação e Síntese de Informação obtida Por Escalas Likert. In: Encontro de Ensino e Pesquisa em Contabilidade e Administração, 3, 2011, João Pessoa Anais [...], João Pessoa: EnEPQ, 2011.

SGUISSARDI, V. Educação Superior no Brasil. Democratização ou massificação mercantil? Educ. Soc., Campinas, v. 36, n. 133, p. 867-889, out.-dez., 2015 Disponível em: 
http://www.scielo.br/pdf/es/v36n133/1678-4626-es-36-133-00867.pdf . Acesso em: 23 jan. 2019.

SGUISSARDI, V. Modelo de expansão da educação superior no Brasil: predomínio privado/mercantil e desafios para a regulação e a formação universitária. Educação e Sociedade, Campinas v. 29, n. 105, set./dez., 2008. Disponível em: http://www.scielo.br/scielo.php?pid=S010173302008000400004\&script=sci_abstract\&tlng=pt. Acesso em: 24 de fev. 2019.

SOUZA, Daniele Graciane; SILVEIRA, Adriana Dragone. O direito à educação e a permanência estudantil na UFPR: uma análise da política de assistência estudantil. Educação e Fronteiras On-Line, Dourados -MS, v. 6, n. 16, 2016, p. 106 - 119. Disponível em: http://ojs.ufgd.edu.br/index.php/educacao/article/view/5700. Acesso em: 28 de jul. de 2019.

SUPERINTENDÊNCIA TECNOLOGIA DA INFORMAÇÃO - STI/ UFPB. 2016. Disponível em: http://www.ufpb.br/content/sti-informe. Acesso em: 11 nov. 2018.

XYPAS, C. Condições sociológicas do êxito escolar de alunos de origem popular. Crítica Educativa, Sorocaba/SP, v. 3, n. 1, p. 5-18, jan./jun., 2017. Disponível em: http://www.criticaeducativa.ufscar.br/index.php/criticaeducativa/article/view/214/243. Acesso em: 23 jan. 2019.

XYPAS, C.; SANTOS, S. C. M. Reconhecimento social e sucesso escolar de alunos de origem popular: aspectos teórico-metodológicos. In: SOUSA, A.T.; ARAUJO, H. M. L. Investigação em educação: diversidade de saberes e de práticas. Teresina: Imprece Editora, vol. 3, 2015, p. 215-227.

ZAGO, N. Do acesso à permanência no ensino superior: percursos de estudantes universitários de camadas populares camadas. Revista Brasileira de Educação, v. 11, n. 32, p.226-238, maio/ago. 2006. Disponível em:

http://www.scielo.br/pdf/rbedu/v11n32/a03v11n32.pdf Acesso em: 20 de jan. 2019.

Recebido em: 30/01/2020

Aprovado: 26/03/2020 